$16^{\circ}$ USIHC - Congresso Internacional de Ergonomia e Usabilidade de USIHC Interfaces Humano Computador

\title{
AVALIAÇÃO DAS CONDIÇÕES DE MICROACESSIBILIDADE FÍSICA EPAISAGÍSTICAS NAS RUAS LIBERATO BARROSO E GUILHERME ROCHA
}

\author{
EVALUATION OF THE CONDITIONS OF PHYSICAL \\ MICROACCESSIBILITY AND LANDSCAPE IN THE STREETS \\ LIBERATO BARROSO AND GUILHERME ROCHA
}

Raquel Pessoa Moranoํㅜ, Mestranda

Fernanda Rocha ${ }^{2}$, D.Sc

(1) Universidade Federal do Ceará (UFC)

e-mail: raquelmorano20@gmail.com

(2) Universidade de Fortaleza (UNIFOR)

e-mail: fernandarocha@unifor.br

Palavras-chave: Acessibilidade, Espaço Público, Ruas de pedestre.

O presente trabalho trata de questões referentes à acessibilidade no espaço público. Tem como objetivo analisar e comparar as ruas Liberato Barroso e Guilherme Rocha em relação as Normas de acessibilidade. Em face das exigências de um mundo diversificado, o estudo busca a percepção o espaço público e como esse vem sendo construído. As análises foram feitas de acordo com as leis de inclusão e acessibilidade (NBR9050) e traz resultados qualitativos do espaço construído.

Key words: Accessibility, Public Space, Pedestrian Streets.

This paper deals with issues related to accessibility in the public space. Its objective is to analyze and compare Liberato Barroso and Guilherme Rocha Streets in relation to the Accessibility Standards. In view of the demands of a diverse world, the study seeks to perceive the public space and how it has been constructed. The analyzes were done according to the laws of inclusion and accessibility (NBR9050) and brings qualitative results of the built space. 


\section{$16^{\circ}$ \\ ERGODESIGN USIHC CINAHPA}

\section{Introdução}

$\mathrm{O}$ acelerado crescimento demográfico das cidades brasileiras - que segundo dados do IBGE (2000), em 1940 o Brasil era considerado um país rural com $70 \%$ da população morando no campo e, já em 2000, mais de $82 \%$ da população brasileira era urbana - trouxe como consequência muitas dificuldades que provocam a sociedade e o poder público constituído. Entre elas, a carência de acessibilidade urbana que atinge mais intensamente as Pessoas com Deficiência (auditiva, visual, mental e motora) e as Pessoas com Dificuldade de Locomoção. Apresenta-se em boa parte dos espaços púbicos inadequação do atendimento das necessidades básicas de acesso por todas as pessoas. A precária condição de acessibilidade pode comprometer sensivelmente a sustentabilidade da cidade, que segundo o Ministério das Cidades (2004) a entende como a compatibilização do seu crescimento e eficiência econômica com a conservação ambiental, a qualidade de vida e equidade social.

Segundo o Censo (2010), 23,9\% da população brasileira possuía pelo menos uma das deficiências investigadas: visual; auditiva; motora e mental ou intelectual. A Região Nordeste apresentou a maior taxa de prevalência de pessoas com uma dessas deficiências - $26,6 \%$ e no Ceará a taxa foi de $27,6 \%$, o que implica urgência da necessidade da população para prática de ações voltadas à melhoria da acessibilidade, consequentemente de um fortalecimento de cidadania.

Diante desse quadro, percebeu-se a importância de se analisar as condições de acessibilidade nos espaços públicos mais especificamente as ruas Liberato Barroso e Guilherme Rocha com foco nos trechos entre a Praça do Ferreira e a Praça José de Alencar por ser o intervalo de maior volume de pedestres e por terem sido as primeiras $16^{\circ}$ Ergodesign - Congresso Internacional de Ergonomia e Usabilidade de Interfaces Humano Tecnológica: Produto, Informações Ambientes Construídos e Transporte

$16^{\circ}$ USIHC - Congresso Internacional de Ergonomia e Usabilidade de Interfaces Humano Computador

CINAHPA | 2017 - Congresso Internacional de Ambientes Hipermídia para Aprendizagem.

implantadas na cidade, e apresentar diagnósticos relacionados as questões físicas e qualitativas do lugar.

O presente artigo tem o intuito de verificar a que nível se encontra a produção do espaço urbano tendo em vista as exigências de um mundo diversificado em que a circulação sem restrições e sem barreiras é de direito para pessoas de todos os grupos. A rua apresenta-se como local público de circulação, permanência, lazer e trabalho, sendo peça chave para a saúde urbana. $\mathrm{O}$ contexto anteriormente referido, é resultado do curso feito em 2016 de Projeto Bioclimático e Sustentável do programa de Pós-Graduação de Arquitetura e Urbanismo da Universidade de Fortaleza (UNIFOR).

Foi utilizado como base para definição dos critérios de comparação e análise os princípios do Desenho Universal (PREISER, 2001; CAMBIAGHI, 2007: CEPAM, 2008), conceitos como o da exclusão espacial (DUARTE; COHEN et al, 2013) e como parâmetros as normas e leis sobre o assunto (Decreto 5.296/2004; NBR 9050/2004; CEARÁ, 2009).

\section{Objetivo}

Analisar o quanto as referidas ruas no centro de Fortaleza - CE, enquanto espaço público, atendem a pré-requisitos necessários para que funcionem como agregadores de pessoas, oferecendo condições de conforto ambiental e de circulação sem limitações e obstáculos.

\section{Justificativa}

A investigação acontecerá no Bairro Centro, pois além de ter sido o primeiro núcleo urbano da cidade e ser considerado o bairro histórico da cidade, se mantem com um intenso movimento, 


\section{$16^{\circ}$ \\ ERGODESIGN USIHC CINAHPA}

embora a população residente tenha diminuído gradativamente pela forma como a cidade se desenvolveu, criando uma espécie de especialização funcional do bairro, que é - quase predominantemente comercial. Assim, existe um grande fluxo de pessoas circulando a pé, além dos veículos particulares e do transporte coletivo.

A pesquisa se desenvolve nas primeiras ruas de pedestre do centro de Fortaleza: Rua Liberato Barroso e Rua Guilherme Rocha - esta já de uso exclusivo de pedestre desde 1956 e consolidadas pelo plano de Hélio Modesto de 1963. Estão localizadas entres as praças de maior movimento do centro, a Praça do Ferreira e a Praça José de Alencar, e pontos comerciais são extremamente disputados por empresários.
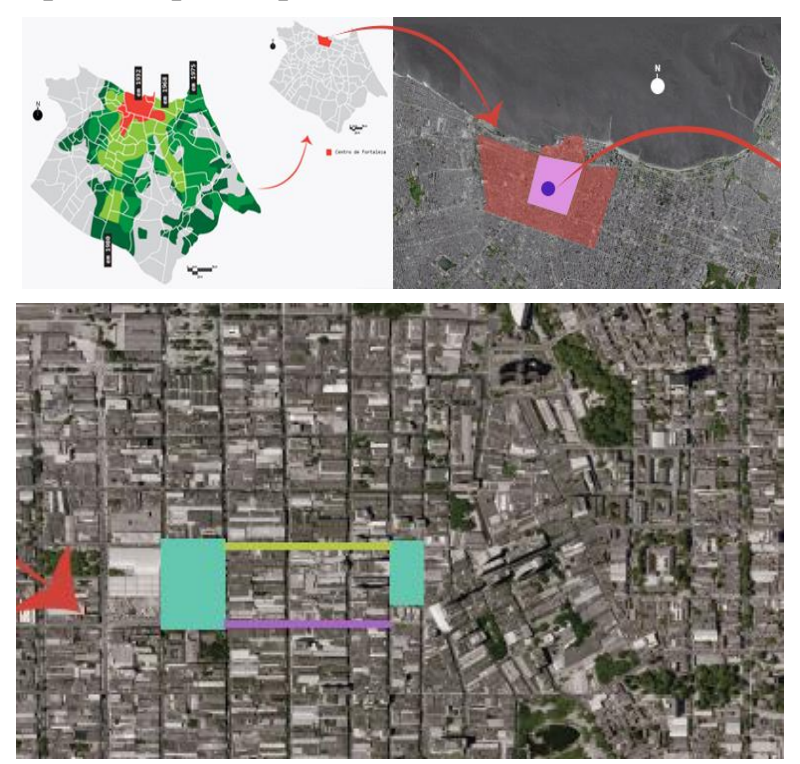

Figura 01 (da Esquerda para direita): Evolução Urbana da cidade de Fortaleza, em vermelho localiza-se o bairro Centro; Bairro Centro em vermelho, em rosa o chamado centro histórico e o ponto roxo demarca onde estão localizadas as ruas e por fim, com uma visão mais ampliada na terceira imagem, as ruas Liberato Barroso e Guilherme Rocha entre as praças do Ferreira e José de Alencar. Fonte: Google Earth com adaptação do autor.

Porém, relatos em entrevistas no Jornal Tribuna do $16^{\circ}$ Ergodesign - Congresso Internacional de Ergonomia e Usabilidade de Interfaces Humano Tecnológica: Produto, Informações Ambientes Construídos e Transporte

$16^{\circ}$ USIHC - Congresso Internacional de Ergonomia e Usabilidade de Interfaces Humano Computador

CINAHPA | 2017 - Congresso Internacional de Ambientes Hipermídia para Aprendizagem.

Ceará (2014) e Diário do Nordeste (2014) de pessoas que circulam por essas ruas, dão conta da existência de muitos buracos e de galerias de esgoto abertas, além disso, a circulação é dificultada por vendedores informais que estrangulam a passagem do pedestre e cadeirante.

Essa é só uma das situações conflituosas do espaço e, por isso, a importância da análise sob questões de conforto paisagístico e acessibilidade para pessoas com deficiência e mobilidade reduzida, uma vez que tais públicos apresentam crescimento contínuo e precisam ser atendidos perante as questões de mobilidade urbana e pelo direito de ir e vir de qualquer cidadão.

\section{Metodologia}

A pesquisa, de caráter qualitativo e exploratório, com pesquisa de campo, utiliza-se da observação direta e intensiva em diferentes dias, turnos e horários, o que traz novos aspectos a cada observação. "A observação é uma técnica de coleta de dados para conseguir informações e utilizar os sentidos na obtenção de determinados aspectos da realidade. Não consiste apenas em ver e ouvir, mas também em examinar fatos e fenômenos que se desejam estudar. " (MARCONI e LAKATOS, 1996, p. 79).

O método utilizado para a realização dessas vistorias foi a observação e a investigação in loco bem como a aplicação de checklists com critérios de acessibilidade pré-estabelecidos com base nos princípios do Desenho Universal (PREISER, 2001; CAMBIAGHI, 2007; al, 2013), tendo como parâmetros as normas e leis sobre o assunto (Decreto 5.296/2004; NBR 9050/2015; CEARÁ, 2009; GUIA DE ACESSIBILIDADE, 2008). Elaborou-se então um conjunto de critérios de avaliação e a sua evolução ao longo das vistorias feitas, com modificações que objetivaram a melhoria do processo de análise, considerando
Realização:

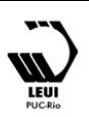




\section{$16^{\circ}$ \\ ERGODESIGN USIHC CINAHPA}

peculiaridades que foram fazendo-se necessárias conforme as visitas subsequentes.

Para analisar os critérios desenvolveram-se fichas para transcrever a situação das ruas, assim, tinham as opções: ( ) sim, ( ) não, ( ) não se aplica e espaços para observações. Isto possibilitou um diagnóstico com dados importantes para a comparação.

Uma observação importante a se fazer é que as duas ruas de pedestre, tanto a Liberato Barroso, quanto a Guilherme Rocha, possuem cruzamentos com vias nas quais existe tráfego de automóveis, bicicletas e transporte coletivo. Assim, foram analisadas também, a travessia dessas ruas.

Os critérios de avaliação foram os seguintes:

\subsection{Quanto ao Passeio}

Estado de conservação;

Existência de pavimentação adequada;

Tipo de pavimentação;

Existência de passagens estreitas de circulação;

Existência de pelo menos uma rota acessível.

\subsection{Sobre a vegetação}

Existência de vegetação que interrompe o percurso;

Existência de raízes que danificam a pavimentação;

Existência de espécies espinhosas;

Existência de espécies venenosas;

Espécies que liberam frutos ou resina sobre o piso;

Existência de galhos podados deixando livre $16^{\circ}$ Ergodesign - Congresso Internacional de Ergonomia e Usabilidade de Interfaces Humano Tecnológica: Produto, Informações Ambientes Construídos e Transporte

$16^{\circ}$ USIHC - Congresso Internacional de Ergonomia e Usabilidade de Interfaces Humano Computador

CINAHPA | 2017 - Congresso Internacional de Ambientes Hipermídia para Aprendizagem.

\section{$2,10 \mathrm{~m}$.}

\subsection{Quanto às travessias e guias rebaixadas}

Largura mínima 1,20m;

Abas laterais da rampa com largura de $50 \mathrm{~cm}$;

Abas laterais com inclinação recomendada 10\%;

Inclinação 8,33\%;

Desnível entre o término da rampa e o leito carroçável;

Localização da guia rebaixada junto à faixa do pedestre;

Rampas alinhadas entre si dos lados opostos da via;

Piso tátil de alerta;

Piso tátil direcional conectando a rampa da travessia;

4.4. Sobre o piso tátil de alerta e direcional, contendo ainda espaços para observações $e$ anotações:

No início e no término das rampas;

Junto a desníveis e rebaixamento de calçadas;

Em torno dos obstáculos suspensos com altura entre $0,60 \mathrm{~m}$ e $2,10 \mathrm{~m}$;

Na faixa de pedestre.

Estavam ainda presentes na ficha de análise o mobiliário urbano e outros elementos do espaço urbanos, como: telefone público; caixas de correio; bancos; lixeiras; banca de revista; jardineiras; semáforo sonoro nas travessias; placas; postes; barreiras aéreas ou no piso.
Realização:

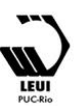




\section{$16^{\circ}$ \\ ERGODESIGN USIHC CINAHPA}

Assim, após algumas visitas para análise dos critérios escolhidos, foi adotado um novo modelo de ficha com os critérios melhores elaborados para a consideração do que vem a ser uma rua acessível. Algumas considerações sobre a escolha dos elementos da análise.

Considerou-se importante verificar o percurso passeio, a observação do tipo de piso e seu estado de conservação. A análise desse critério foi um dos mais importantes pois está presente em todo o caminho, assim, podendo apresentar um piso não adequado, mal assentado, sem manutenção, além de disso, buracos, bueiros sem tampa e obstáculos apresentando perigo para as pessoas, cadeirantes, pessoas com mobilidade reduzida, crianças e idosos. Portanto, foi um dos itens indispensáveis para a análise.

Verificou-se se havia uma rota acessível com guias ou pisos direcionais que abrangesse o uso universal. Ainda referente aos passeios, analisou-se se as passagens eram muito estreitas, pois elas são empecilhos para o trajeto dos cadeirantes, pessoas com obesidade ou ainda pessoas que usam muletas.

Após a análise dos passeios, foram avaliadas as travessias e as guias rebaixadas, pois existiam pontos conflitantes nos cruzamentos sendo ruas de pedestre com ruas para carros, assim a comunicação entre elas e a continuação da rua de pedestre é caótica e priorizando sempre os carros. Segundo a NBR 9050:2015, os rebaixamentos das calçadas devem possuir abas laterais de inclinação máxima de 10\% (1:10). Baseando-se nessas premissas, foram formulados critérios que dizem respeito às medidas e inclinações das guias rebaixadas para que sejam avaliadas como acessíveis ou não. Ainda em relação à guia rebaixada, observou-se se existe um desnível entre o término da guia e o leito carroçável, pois essa existência constitui a inviabilização da mesma, já que dificulta ou até impede a passagem da cadeira $16^{\circ}$ Ergodesign - Congresso Internacional de Ergonomia e Usabilidade de Interfaces Humano Tecnológica: Produto, Informações Ambientes Construídos e Transporte

$16^{\circ}$ USIHC - Congresso Internacional de Ergonomia e Usabilidade de Interfaces Humano Computador

CINAHPA | 2017 - Congresso Internacional de Ambientes Hipermídia para Aprendizagem. de rodas.

Além disso, é importante que as guias rebaixadas estejam localizadas em lados opostos estejam alinhadas entre si e com a faixa de pedestre. Esse alinhamento é necessário para que a travessia possa ser feita de forma direta, sem fazer com que o usuário corra perigo ou constrangimentos. A implantação de piso tátil de alerta e direcional nas guias rebaixadas é importante para que a acessibilidade seja alcançada também pelos deficientes visuais.

A vegetação existente ao longo das ruas foi analisada de forma a perceber se as raízes das árvores danificavam o piso, se interrompiam as rotas acessíveis e se os galhos estavam podados de forma a deixar uma altura livre de $2,10 \mathrm{~m}$.

Após a definição dos critérios e a importância de cada um, fez-se um mapa feito para melhor entendimento da rota das ruas e dos pontos de conflito (cruzamentos). Assim, pôde-se fazer anotações in loco diretamente no mapa, o que facilitou a visualização e entendimento da situação das ruas, além disso, foram feitos registros fotográficos para a confirmação da análise e verificação de alguns outros pontos que possam ter passado despercebidos quando no local.

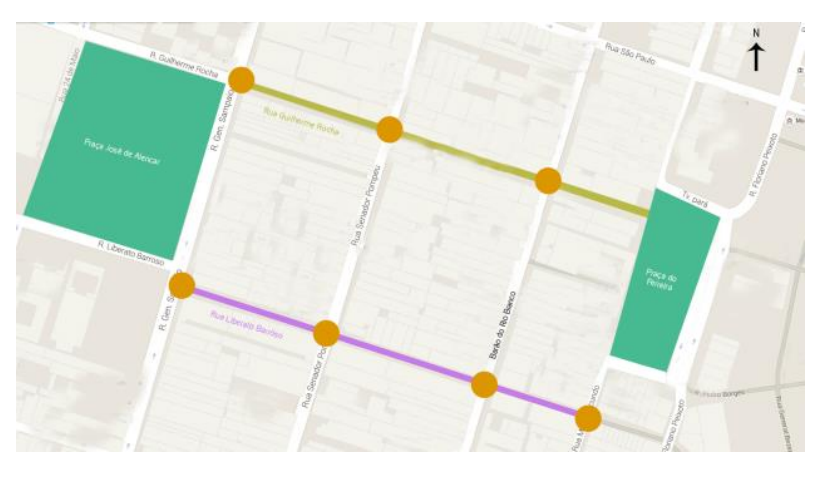

Figura 02: planta de situação usada para anotações in loco. Fonte: Google Maps com adaptação do autor. 


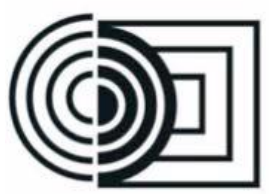
CINAHPA

Levou-se em consideração, também, sensações e impressões com relação às ruas com o objetivo de uma avaliação subjetiva. Os seguintes aspectos foram anotados: existência de espaços de convivência e permanência; arborização e sombreamento; presença de funções diversificadas; quiosques; barracas de comida.

Esta percepção subjetiva do espaço público, vem sendo trabalhada em Duarte; Cohen et al (2013) cujo estudo da metodologia para diagnóstico de acessibilidade em centros urbanos se apoia no conceito de Exclusão Espacial desenvolvido por Duarte e Cohen encara o espaço como um ator que se relaciona com o usuário de forma a excluí-lo ou a incluí-lo no âmbito de uma inter-relação espacial. A Exclusão Espacial acontece quando os espaços se transformam na materialização das práticas segregatórias e da visão de mundo e de sociedade que dá menor valor às diferenças - sociais ou físicas (GUERREIRO, 2011).

\subsection{Resultados}

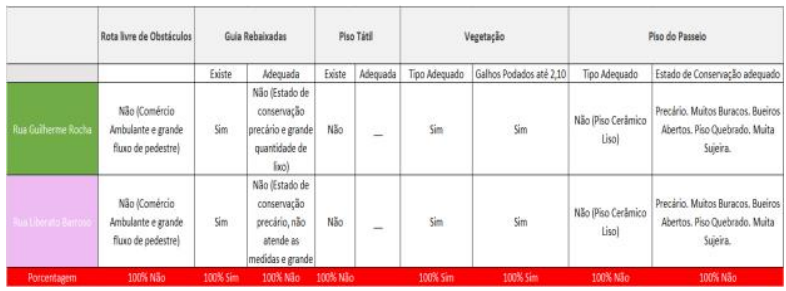

Apresentamos resultados referentes a: rota livre de obstáculos; guias rebaixadas; piso tátil; vegetação; tipo de piso e seu estado de conservação. Estes resultados foram colocados em uma tabela gerada a partir de critérios de acessibilidade adotados para avaliação das ruas.

\subsection{Quanto à rota livre de obstáculos;}

Nas duas ruas o resultado foi semelhante. Pode-se afirmar que não há uma rota totalmente livre.

Sempre há barracas de comércio informal, postes, lixeiras, barracas de comida e canteiros de árvores. $16^{\circ}$ Ergodesign - Congresso Internacional de Ergonomia e Usabilidade de Interfaces Humano Tecnológica: Produto, Informações Ambientes Construídos e Transporte

$16^{\circ}$ USIHC - Congresso Internacional de Ergonomia e Usabilidade de Interfaces Humano Computador

CINAHPA | 2017 - Congresso Internacional de Ambientes Hipermídia para Aprendizagem.

Além disso, foi constatado a ausência de piso tátil direcional e de alerta ou guia contínua que proporcione pessoas com deficiência visual perceber as condições de circulação, orientar-se e locomover-se por meio de alguma sinalização.

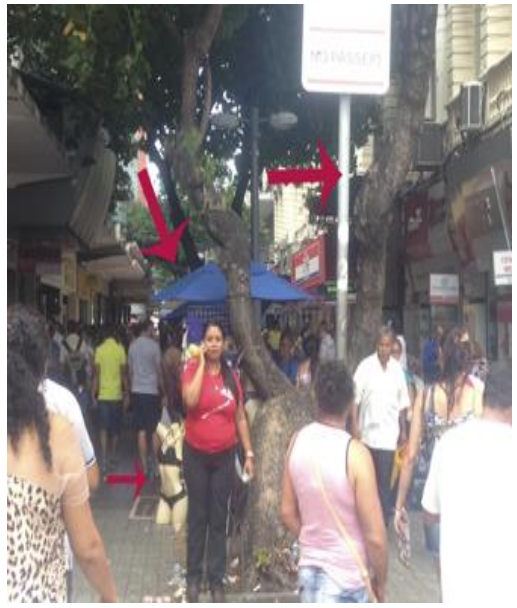

Figura 03: Rua Guilherme Rocha Fonte: Google Earth.

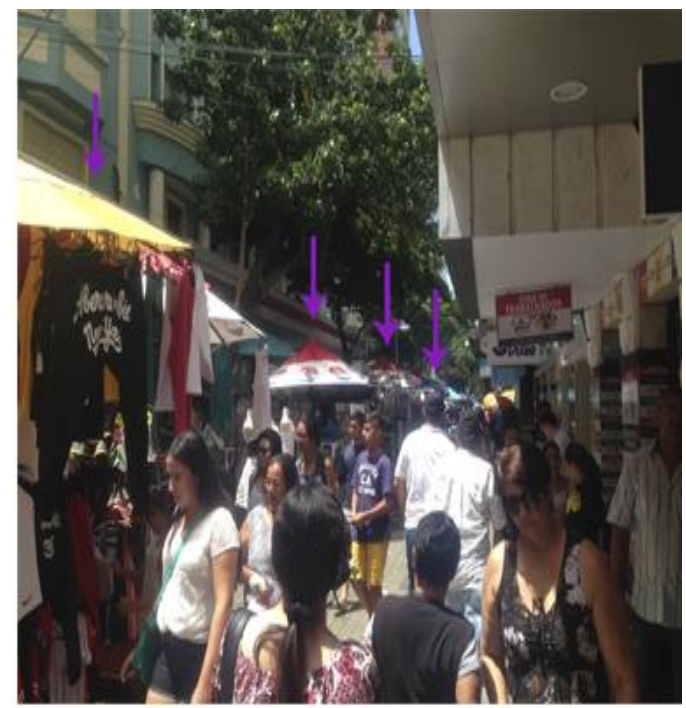

Figura 04: Rua Guilherme Rocha. Fonte: Acervo Pessoal 


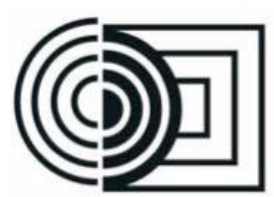
CINAHPA

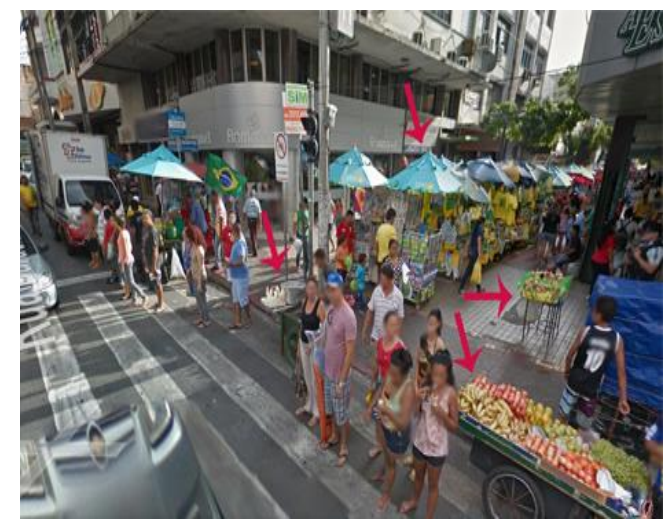

Figura 05: Rua Guilherme Rocha Fonte: Acervo Pessoal.

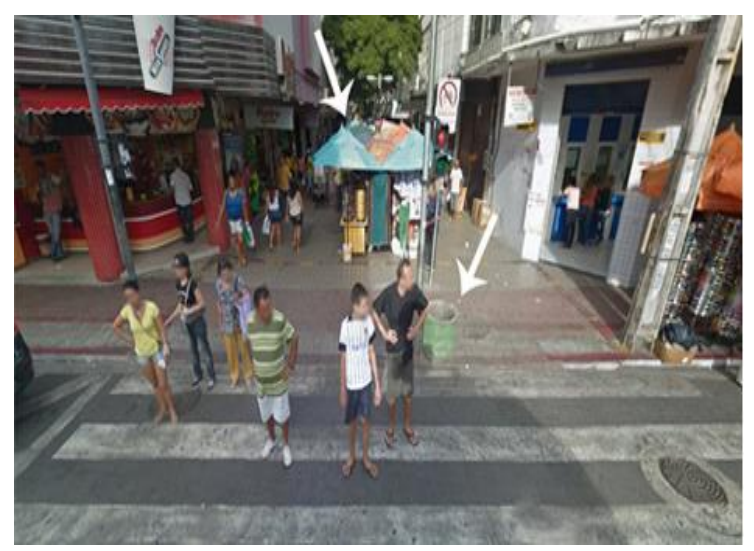

Figura 06: Rua Liberato Barroso. Nas imagens é forte a percepção da quantidade de pessoas e obstáculos.

Fazendo-se um ambiente confuso e inapropriado para pessoas com deficiência física e visual circularem. Fonte: Google Earth.

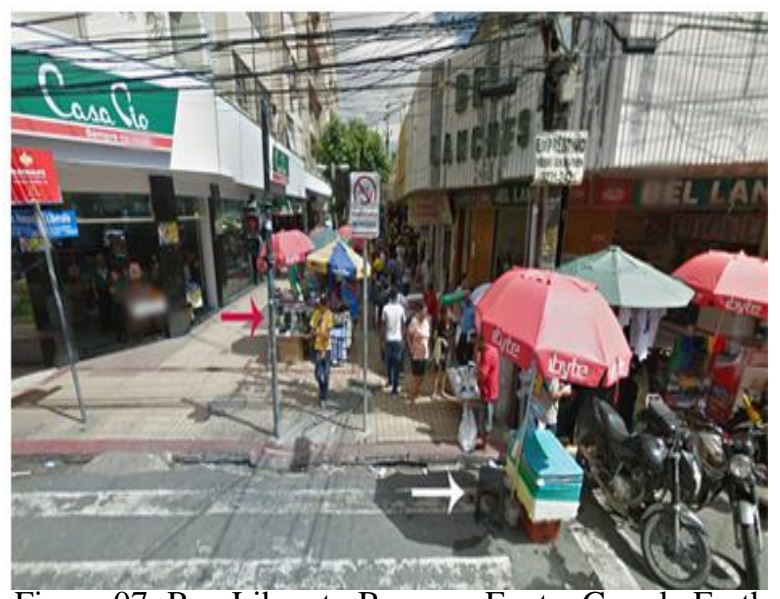

Figura 07: Rua Liberato Barroso. Fonte: Google Earth. $16^{\circ}$ Ergodesign - Congresso Internacional de Ergonomia e Usabilidade de Interfaces Humano Tecnológica: Produto, Informações Ambientes Construídos e Transporte

$16^{\circ}$ USIHC - Congresso Internacional de Ergonomia e Usabilidade de Interfaces Humano Computador

CINAHPA | 2017 - Congresso Internacional de Ambientes Hipermídia para Aprendizagem.

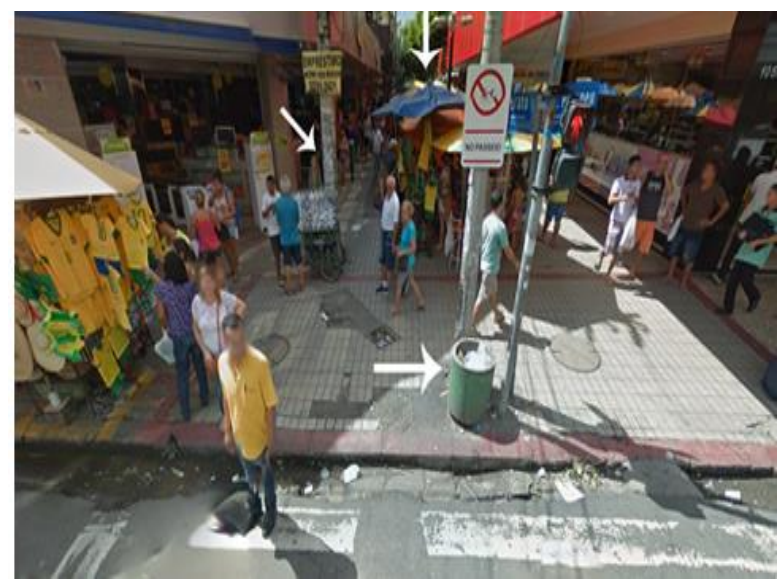

Figura 08: Rua Liberato Barroso. Fonte: Google Earth.

\subsection{Quanto as guias rebaixadas;}

As guias estão presentes em todas as travessias (cruzamentos), porém, nenhuma atende os padres da norma, não possuem nenhuma sinalização e estão em um estado de conservação precário. Além disso, existe muito lixo dificultando a passagem e criando obstáculos. E, mais uma vez, constatou-se a ausência de piso tátil.

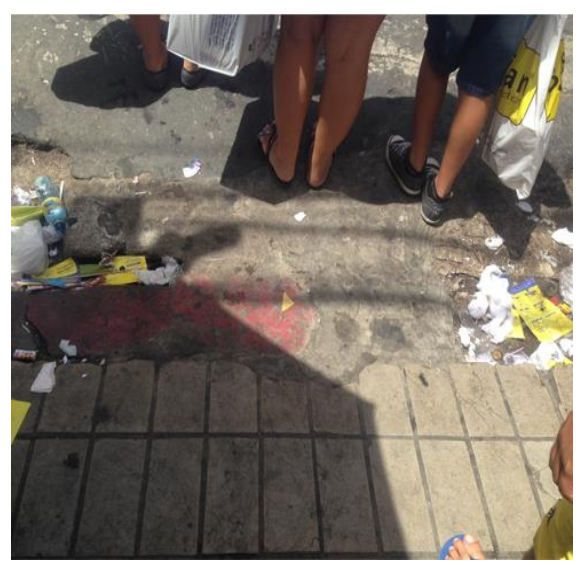

Figura 09: Lixo acumulado, estado precário e tamanho inapropriado segundo à norma. Fonte: Acervo Pessoal. 


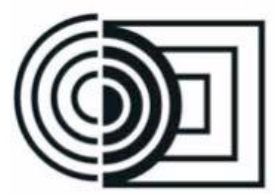

\section{$16^{\circ}$}

ERGODESIGN USIHC CINAHPA

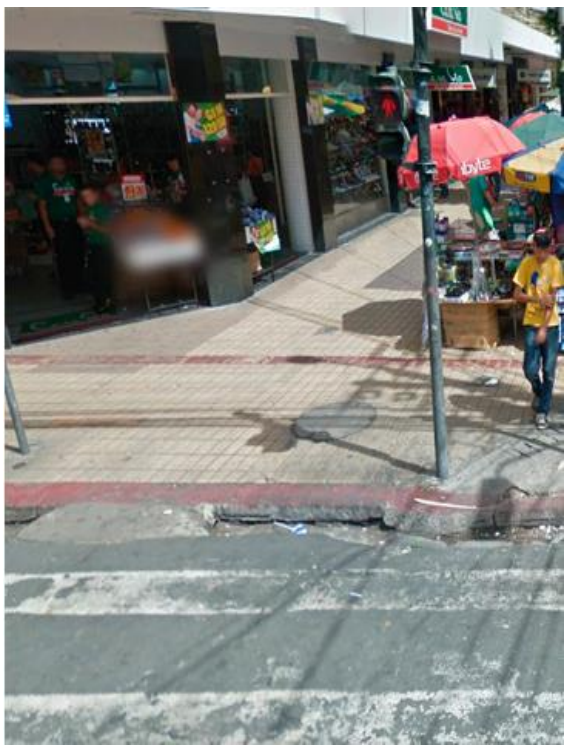

Figura 10: Tamanho inapropriado segundo à norma $\mathrm{e}$ estado precário e muito obstáculos. Fonte: Google Earth.

\subsection{Quanto a Vegetação;}

A vegetação encontrada nas ruas é de tipo adequado e possui seus galhos podados numa altura de 2,10 evitando barreiras aéreas. Além disso, traz um conforto ambiental para as pessoas que passam por ali e, principalmente, as que trabalham o dia inteiro, trazendo sombra e sensação de bem estar.

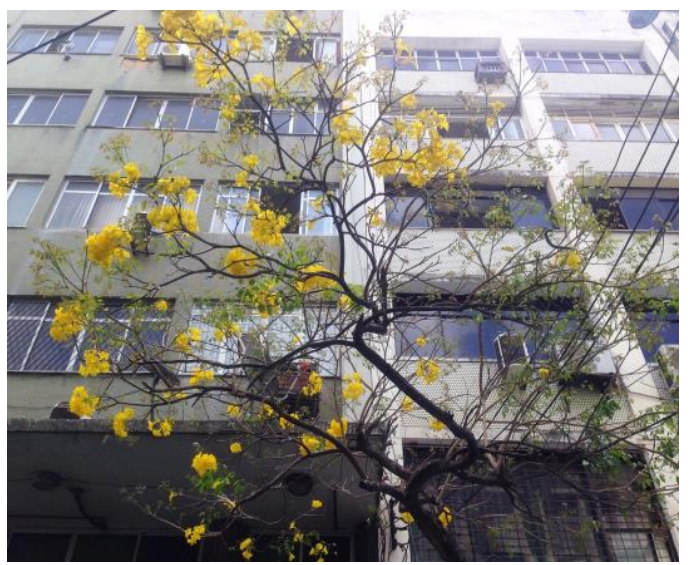

Figura 11: Tipos de vegetação e como elas estão locadas no espaço (normalmente, no centro das ruas). Fonte: Acervo Pessoal. $16^{\circ}$ Ergodesign - Congresso Internacional de Ergonomia e Usabilidade de Interfaces Humano Tecnológica: Produto, Informações Ambientes Construídos e Transporte

$16^{\circ}$ USIHC - Congresso Internacional de Ergonomia e Usabilidade de Interfaces Humano Computador

CINAHPA | 2017 - Congresso Internacional de Ambientes Hipermídia para Aprendizagem.

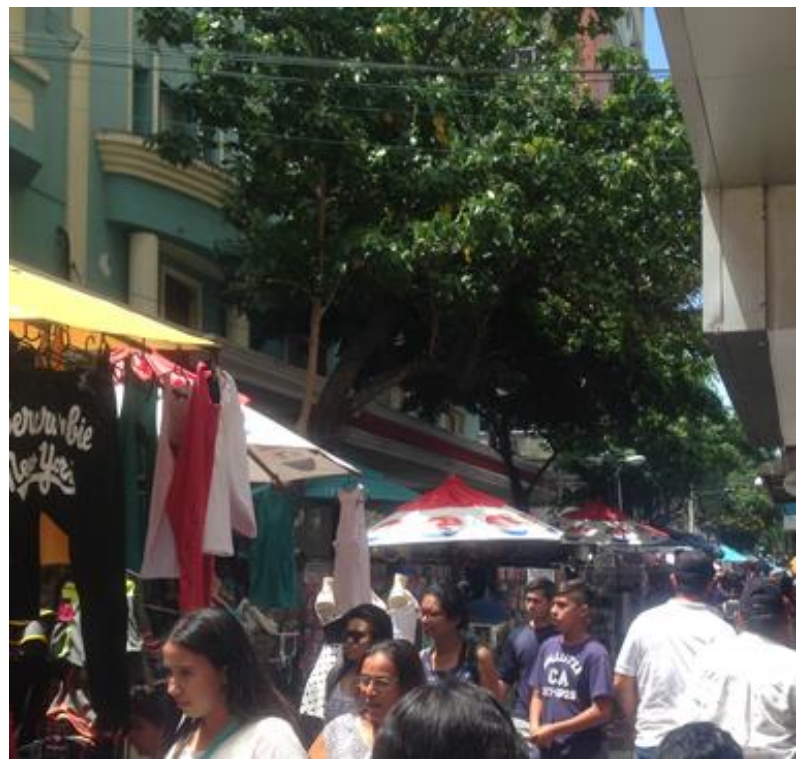

Figura 12: Tipos de vegetação e como elas estão locadas no espaço (normalmente, no centro das ruas). Fonte: Acervo Pessoal.

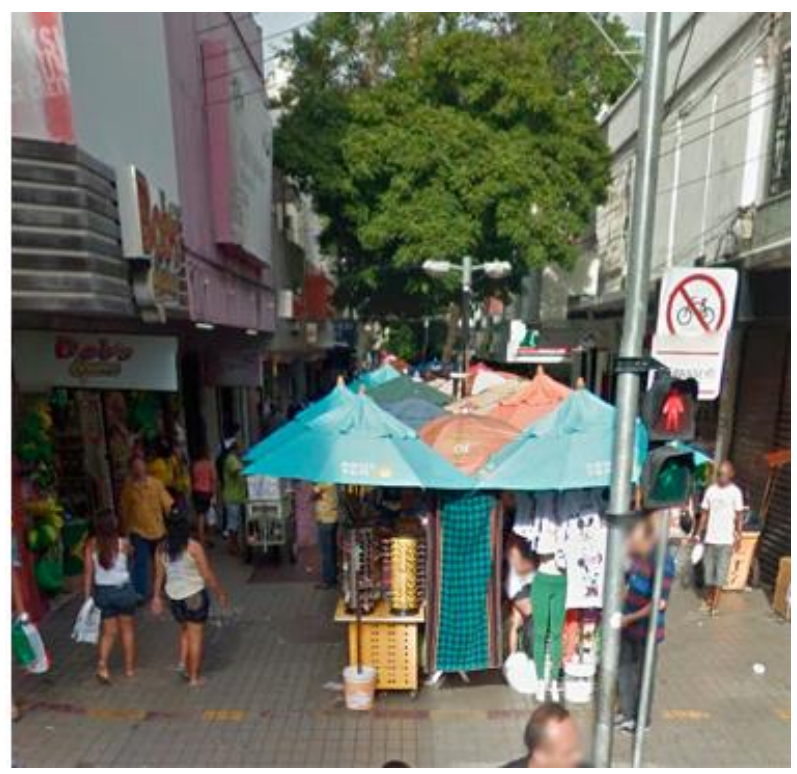

Figura 13: Tipos de vegetação e como elas estão locadas no espaço (normalmente, no centro das ruas). Fonte: Acervo Pessoal. 


\section{$16^{\circ}$ \\ ERGODESIGN USIHC CINAHPA}

\subsection{Quanto ao Piso do Passeio;}

O piso é inadequado para o uso pois, constitui-se se uma cerâmica lisa que pode ser perigosa para as pessoas com deficiências ou não. Além disso, a situação do piso está precária com várias partes quebradas, buracos e tampas de galeria de esgoto abertas ou quebradas.

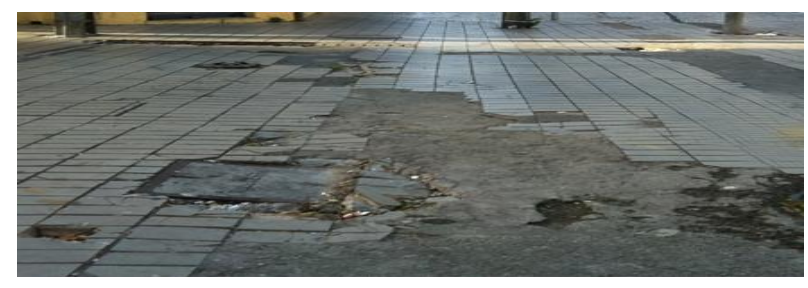

Figura 14: Situação do piso dos passeios. Fonte: Acervo Pessoal.

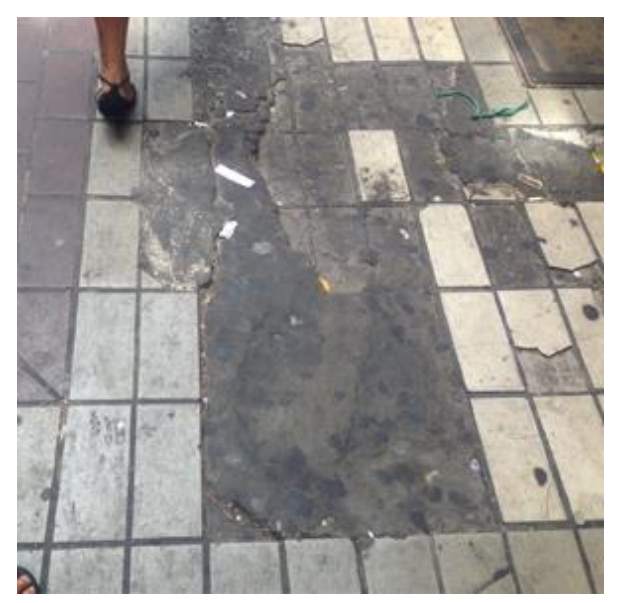

Figura 14: Situação do piso dos passeios. Fonte: Acervo Pessoal. $16^{\circ}$ Ergodesign - Congresso Internacional de Ergonomia e Usabilidade de Interfaces Humano Tecnológica: Produto, Informações Ambientes Construídos e Transporte

$16^{\circ}$ USIHC - Congresso Internacional de Ergonomia e Usabilidade de Interfaces Humano Computador

CINAHPA | 2017 - Congresso Internacional de Ambientes Hipermídia para Aprendizagem.

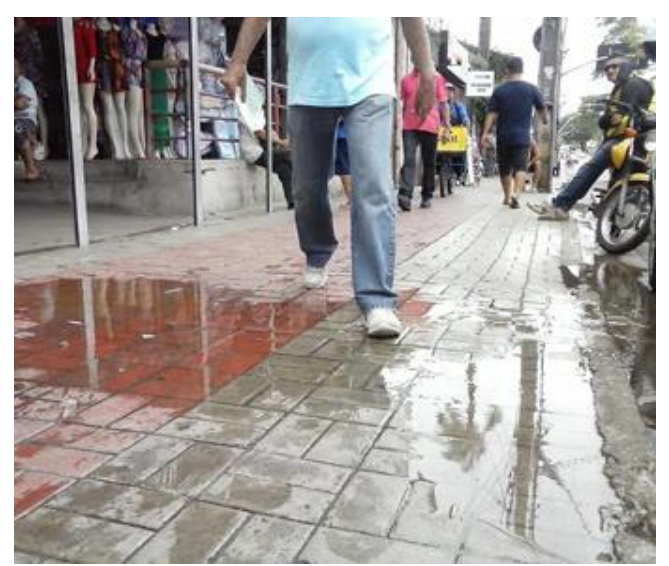

Figura 15: Situação do piso dos passeios. Fonte: Acervo Pessoal.

Em relação à análise subjetiva, sobre as sensações e impressões que se teve em relação as ruas foi que não oferecem condições de convivência e permanência. Além disso, a acessibilidade não é atendida. Existe uma especialização funcional nas ruas predominante de comércio, assim, no final do expediente a rua fica completamente suja e vazia. O único interesse das pessoas que transitam por ali é atravessar de uma praça para a outra e pelo comércio.

\section{Considerações Finais}

Verificou-se um grande potencial nas ruas, porém, encontram-se em estado precário e "esquecidas" pelo poder público. Além disso, é prejudicial a especialização funcional, pois só existe um atrativo para as ruas que é o comércio. Não há espaço para convivência, não há lanchonetes e nem mobiliário urbano, tudo gira em torno de compras e vendas.

Sobre a análise dos dados coletados, pode-se dizer que a situação das ruas é precária só atende a um item dos critérios de análise (vegetação). Assim, é um espaço público que exclui as pessoas com dificuldade de locomoção, deficientes visuais, auditivos e cadeirante. Além disso, percebemos o descaso as Prefeitura com uma das ruas mais importantes do Centro, que contém história e memória e a falta de fiscalização perante as normas
Realização:

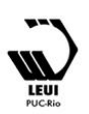




\section{$16^{\circ}$ \\ ERGODESIGN USIHC CINAHPA}

da ABNT que trazem recomendações sobre o assunto, como é o caso da NBR 9050/2015.

Não é só uma questão de atendimento às leis e normas, mas falta uma política de inclusão, em que abram a cidade para todas as pessoas de modo a incluir suas necessidades de locomoção. Para isso, é necessário a continuação de estudos e pesquisas para que os projetos, obras e fiscalizações estejam alinhados com as normas e legislações. Assim, a esperança é que os espaços urbanos sejam cada vez mais pensados em prol da inclusão de todos.

\section{Referências}

\section{ASSOCIAÇÃO BRASILEIRA DE NORMAS} TÉCNICAS (ABNT). NBR 9050: Acessibilidade a edificações, mobiliário, espaços e equipamentos urbanos. Rio de Janeiro, 2015.

BRASIL. Decreto $N^{\circ}$ 5.296, de 2 de Dezembro de 2004, que regulamenta as Leis $n^{\circ}$ s10.048, de 8 de novembro de 2000, que dá prioridade de atendimento às pessoas que especifica, e 10.098, de 19 de dezembro de 2000, que estabelece normas gerais e critérios básicos para a promoção da acessibilidade das pessoas com deficiências ou com mobilidade reduzida.

\section{CAMBIAGHI, Silvana. Desenho Universal:} métodos e técnicas para arquitetos e urbanistas. São Paulo. Editora Senac São Paulo, 2007.

CEARÁ. Guia de Acessibilidade: espaços públicos e edificações. Elaboração: Nadja G. S. Dutra Montenegro; Zilsa Maria Pinto Santiago; Valdemice Costa de Sousa. Fortaleza: SEINFRACE, 2009.

Diário do Nordeste - Site:

http://blogs.diariodonordeste.com.br/egidio/cidade s/fortaleza-o-centro-esta-feio-e-sujo/. Acesso em: 20.05.2016. $16^{\circ}$ Ergodesign - Congresso Internacional de Ergonomia e Usabilidade de Interfaces Humano Tecnológica: Produto, Informações Ambientes Construídos e Transporte

$16^{\circ}$ USIHC - Congresso Internacional de Ergonomia e Usabilidade de Interfaces Humano Computador

CINAHPA | 2017 - Congresso Internacional de Ambientes Hipermídia para Aprendizagem.
DUARTE, Cristiane Rose de S.; COHEN, Regina et al.(ors). Metodologia para diagnóstico de acessibilidade em centros urbanos: análise de área central da cidade do Rio de Janeiro. Assim: Triunfa Gráfica e Editora. UFRJ. Rio de Janeiro, 2013.

GUERREIRO, Elaine Maria Bessa. A acessibilidade e a educação: um direito constitucional como base para um direito social da pessoa com deficiência. Londrina, 2011 - ISSN 2175-960X - Pg. 3561-3573 3561 - UFSCar

INSTITUTO BRASILEIRO DE GEOGRAFIA E ESTATÍSTICA - IBGE. Censo Demográfico 2000.

Tabelas selecionadas municípios - Disponível em: http://www.ibge.gov.br/censo/default.php

Acesso em: 06 dez. 2015.

MARCONI, M. de A.; LAKATOS, E.M. Técnicas de pesquisa: planejamento e execução de pesquisas, amostragens e técnicas de pesquisas, elaboração, análise e interpretação de dados. 3 ed. Atlas. São Paulo, 1996.

Ministério das Cidades - Perfil da Mobilidade, do Transporte, e do Trânsito nos Municípios Brasileiros. Brasília, DF, dez. 2004. Disponível em:

http://www.cidades.gov.br/index.php?option=conte nt\&task=view\&id=421. Acesso em: 06 dez. 2015.

PREISER, Wolfgang F.E.; OSTROFF, Elaine. Universal Design Handbook. McGraw-Hill. New York, 2001.

Tribuna do Ceará - Site:

http://tribunadoceara.uol.com.br/noticias/fortaleza/ seis-ruas-de-fortaleza-sao-exclusivas-parapedestres-ha-meio-seculo/. Acesso em: 20.05.2016. 